\title{
ESCRITORAS ISRAELENSES DIALOGAM COM A HISTÓRIA
}

Nancy Rozenchan'

Abstract: Contrasting to the first period of Modern Hebrew literature, when books by female authors were not privileged in the national cannon, books by women writers published in the $20^{\text {th }}$ century final years became very popular. Part of this success is due to the historical background adopted by several books of that period. This paper deals with two novels of the period: Shulamit Lapid's book has a woman in the beginning of the $19^{\text {th }}$ century colonization period as its heroine while Shifra Horn's book, dealing with the same period approximately, has several female characters whose names and features remind biblical matriarchs.

Keywords: Hebrew literature, Feminine literature, Israeli literature, Shulamit Lapid, Shifra Horn.

Presente quase que desde o início do período do desenvolvimento da literatura hebraica contemporânea, na década de 1880, a escrita de mulheres não gozou de uma posição de igualdade com a escrita dos autores seus contemporâneos. Mesmo que o papel cultural e formativo de homens e mulheres obedecesse, em teoria, a padrões de igualdade, estabelecidos pela sociedade judaica em formação na Palestina, escritoras não produziram em geral obras que fossem notáveis por algum tipo particular de especificidade.

A partir da década de 1980, uma série de fatores (feminismo, pós-modernismo, estímulo à escrita e número predominante de escritoras e leitoras)

1 Professora associada de língua e literatura hebraicas, Universidade de São Paulo. 
conduz a uma reversão no papel das autoras, que passam a ocupar um espaço apreciável na escrita hebraica em Israel. Não mais sentindo-se obrigadas a acompanhar as grandes questões nacionais e sociais, elas podem dedicar-se ao âmbito do individual, dentro do contexto do coletivo ou não.

Da ampla gama de livros produzidos por escritoras, pretendo ater-me a dois que têm mulheres como suas figuras centrais, ambientados em dois momentos da história e da formação da nação moderna. Inicialmente, Guêi Ôni (O Vale de Ôni), de Shulamit Lapid, autora nascida em Tel Aviv em 1934. Centrado na mulher que ajuda a construir a colônia homônima em 1880, é, em certo sentido, um romance de formação mascarado ou com laivos de romance histórico.

Para esclarecer a particularidade do momento em que se centra a ação, deve-se apontar que é o início do período do surgimento do sionismo moderno. Os judeus sempre invocaram o retorno a Sion em suas preces diárias. Pensadores e humanistas, judeus ou não, trataram, na segunda metade do século XIX, deste retorno. O movimento sionista, que surgiu na Europa nas últimas duas décadas daquele século, visava a um renascimento nacional do povo judeu em seu lar ancestral após quase dois mil anos de exílio estabelecido no período de domínio romano. A par das ideologias, o sionismo consubstanciou-se em atividades práticas, com pequenos grupos que imigraram para a Palestina desde a década de 1880; parte destes sobrevivera a pogroms (estupros, perseguições e matanças organizadas) na Rússia. Na nova terra, algumas destas pessoas procuraram vincular-se ao trato do solo, no que foram, em geral, mal sucedidos, seja pela inexperiência, seja pelas condições extremamente adversas que encontraram. Entretanto, formaram-se colônias agrícolas, mas elas somente iriam vingar vários anos depois.

O enredo do primeiro livro que pretendo apresentar refere-se a uma destas colônias. Guêi Ôni acompanha os primeiros sete anos de Guêi Ôni, uma colônia da Galileia, que viria a se tornar a cidade de Rosh Pina, vistos a partir da posição de uma pioneira.

Fânia, uma sobrevivente de dezesseis anos de um pogrom da Ucrânia, chega à Palestina com um velho tio, um irmão mentalmente perturbado e um bebê não desejado, o produto do estupro. Em sua chegada ao porto de Jafa, ela 
encontra Yehiel, um viúvo de 26 anos, pai de duas crianças, uma das poucas almas corajosas que permaneceram em Guêi Ôni, com quem irá se casar. A severa aridez e o trabalho extenuante, somados à fome, fizeram com que a maior parte dos pioneiros abandonasse o local, deixando para trás algumas poucas famílias tenazes. Fânia lança-se a uma vida de camponesa, tentando extrair a subsistência do solo pedregoso, apesar da fome e da doença. Vestida à moda árabe, ela cavalga pelo país infestado de bandoleiros e irrompe no mundo do comércio, da política e até da defesa dominado pelos homens. Yehiel sucumbe à malária e à exaustão, e Fânia vê-se obrigada a continuar a luta por si.

Enfocarei o livro tanto pela sua personagem como pela sua autoria feminina. Quanto à personagem, ela ilustra a mulher no início da colonização, do movimento sionista prático. Tratarei de mostrar alguns antecedentes literários que falam por si sós e que, paralelamente, são referenciais de ideias da prática sionista da época. É curioso notar que se, por um lado, estes antecedentes literários antecipam ideologicamente conceitos de igualdade que nortearão o movimento sionista e de colonização, por outro, eles logo são ultrapassados por esta prática e considerados retrógrados.

Sirvo-me de alguns exemplos coletados por Rachel Elboim-Dror, em "Mulheres nas utopias sionistas", publicado em hebraico. Todos os modelos são de obras de autoria masculina, escritas em hebraico, alemão ou iídiche e apontam para uma influência do pensamento utópico e, em especial, socialista, quanto à igualdade de sexos e, a partir disto, quanto ao modelo patriarcal da família judaica. Mesmo os exemplos que se encontram no limite do foco de influência igualitária não se liberam de estereótipos sexuais conservadores. $\mathrm{O}$ movimento nacional judaico fez uso da ideia da liberação das mulheres sem que, porém, se modificassem nele as normas básicas no que se referia a elas. Nos textos utópicos, a definição que se apresenta é pelo relacionamento liberal e igualitário em relação às mulheres, mas sendo textos de um sexo apenas, o do universo masculino, o modelo continuou sendo conservador e tradicional. É o que vemos em Di Narn (Os tolos), de Sholem Aleichem, de 1900, em Zukunftsbild (Retrato do futuro), de Edmund Eisler de 1882, em Massa Leerets Israel Bishnat Tav Tav Laelef Hashishi (Viagem à Terra de Israel em 2040), de El'hanan Leib Levinski, de 1892, no mais famoso deles, Altneuland (Velha nova pátria), de 
Theodor Herzl, de 1902, em Yerushalaim Habnuiá (Jerusalém reconstruída), de Boris Shatz, de 1918. Resumindo, cada um à sua moda revelou-se fanaticamente a favor da liberação da mulher de suas funções tradicionais, mas não conseguiu livrar-se totalmente do modelo padronizado de dependência do gosto masculino. Ainda que as mulheres tenham sido um componente importante no enredo em parte considerável das utopias, elas não têm identidade ou voz próprias, não cumprem uma função significativa na revolução sionista e permanecem marginalizadas na nova sociedade, desprovidas de uma consciência a respeito de si mesmas. Em suma, permanecem apolíticas e aceitam as definições masculinas com relação à sua identidade e funções.

Guêi Ôni, o romance de Shulamit Lapid, surge em um momento em que, na literatura hebraica, ocorreu o que Yafa Berlovitsh, uma das diversas estudiosas do assunto, denominou de feminização da literatura hebraica. A maior parte das diversas escritoras que nas décadas de 1980 e 1990 vêm se juntar às que já se manifestavam anteriormente, não vem necessariamente se colocar com uma literatura combatente ou de protesto, mas com uma literatura de presença, que finalmente sai dos bastidores para se mostrar abertamente. Escreviam, sim, mas numa linha que não as definia de forma diversa à da adotada pelos autores masculinos. Não tinham procurado uma especificidade e nem tinham estado desejosas de serem definidas por este viés. Foi só na década de 1980 que as escritoras israelenses, em suas obras ficcionais, eruditas ou em forma de manifestos, trataram de fixar a sua posição como escritoras, para si, na comunidade literária e na receptabilidade de suas obras.

Dentre as motivações destas novas posições houve, como mencionado, o movimento feminista, particularmente pelos seus reflexos em outros países e culturas. As escritoras que surgiram então passaram a fazer ouvir a sua voz de forma direta pela temática trazida, ou de forma indireta, por meio da forma e da linguagem. As escritoras veteranas, de sua parte, ampliaram o seu círculo temático-feminista, carregando este código com conflitos do estranhamento e da hostilidade nos padrões do relacionamento do eu e com próximo. Ainda neste contexto, autoras passaram a revelar a intimidade, deixando de lado a manutenção zelosa da modéstia da privacidade que caracterizara durante décadas as escritoras do país. 
O romance Guêi Ôni prendeu a imaginação do público israelense de uma maneira sem precedentes. Em primeiro lugar, caiu bem no clima de nostalgia que tomou conta do país o país na década de 1980, quando o primeiro centenário da primeira onda imigratória judaica para a Palestina foi celebrado. Shulamit Lapid escreveu o romance em antecipação a 1982. Naquele ano, Rosh Piná, a colônia da Galileia que tinha sido chamada de Guêi Ôni, celebrou o seu centenário. Julgando pela recepção de que o livro gozou, a escolha das datas foi correta; o público demonstrou uma grande fome por um panorama ricamente documentado daquele passado distante filtrado por um prisma ficcional.

Os leitores estavam, sem dúvida, respondendo à novidade de serem introduzidos em uma reconstrução histórica "séria" através dos olhos e da mente de Fânia, a jovem imigrante que se agrega a Guêi Ôni na cena inicial, e permanece a consciência central pela qual a narrativa é focalizada no decorrer do romance.

Isto foi considerado uma inovação. Contestava-se, aí, a ideia de que o movimento pioneiro ou, na realidade, o etos sionista em geral promovera a igualdade das mulheres. Mas isto só aconteceu em teoria. O que a pesquisa recente mostrou é que, na prática, nem os primeiros imigrantes nem a segunda onda imigratória na virada do século XIX para o XX transcenderam as normas patriarcais de suas comunidades de origem na Europa. Por isso, Shulamit Lapid não conseguiu encontrar um modelo histórico para a personagem nos registros de arquivo. Segundo Shulamit Lapid, quando se propôs a escrever o seu livro, realizou uma busca nos arquivos do país referentes ao período, para obter elementos que lhe permitissem idealizar a personagem principal. Entretanto, não houve registro de nenhum modelo feminino de pioneira naquela época e não lhe restou outra alternativa a não ser inventá-lo.

O liviro foi uma tentativa arrojada de fazer justiça às mães fundadoras, de retificar pela ficção os erros da historiografia dominada pelos homens. Não foi um desafio pequeno. A autora precisou criar uma estrutura narrativa que preservasse autenticamente o modo patriarcal de vida de 1880 e, ao mesmo tempo, acomodasse uma protagonista fictícia cujas próprias normas tinham de satisfazer às expectativas feministas contemporâneas. A solução veio na forma de uma colagem, juntando dois gêneros de romance: o épico do colonizador e 
o melodrama romântico. Em um nível, Guêi Ôni é um drama de colonização típico, descrevendo de forma realista as lutas contra toda disparidade do pequeno grupo da Galileia no início da década de 1880. A principal antagonista desta trama é a natureza, a mítica mãe-terra. Neste texto, ela, assim como a jovem Fânia, em sua vida particular, não é uma noiva receptora; quando a narrativa tem início, a terra havia retido as suas dádivas por dois anos seguidos. Severas secas expulsaram a maioria dos pioneiros, deixando apenas umas poucas famílias tenazes e idealistas, incluindo a de Yehiel, o protagonista masculino.

Num outro nível, este é um texto de heroína. É uma história de amor cujos modelos são não apenas os textos canônicos adorados pela protagonista (Anna Karenina, livro que tinha acabado de chegar da Rússia, e os romances de Jane Austen, prediletos de Fânia), mas também romances populares no estilo de Rodolfo Valentino. A autora utilizou-os com grande destreza: Fânia é uma jovem mulher brotando de uma forma consciente, que luta para preservar o seu espírito independente ao mesmo tempo em que, por fim, se apaixona por seu enigmático "príncipe moreno", o marido. Este, por sua vez, é "bonito como o Príncipe de Gales", conforme várias citações, "inteligente como o rei Salomão" e alvo dos ciúmes de todas as mulheres. Previsivelmente ele é também orgulhoso, reticente e distante; ele logo se apaixona por ela, mas mantém isto em segredo. Como nem o leitor nem Fânia ficam sabendo da verdade antes da metade do livro, uma cadeia de desentendimentos e ciúmes românticos constitui a melhor parte do enredo. Mais chocante ainda, há os ecos de Rebecca de Daphne du Maurier: Fânia é recepcionada pelo retrato da falecida esposa, cujas duas irmãs estão convenientemente presentes para evocar a beleza dela e outras qualidades, sempre que podem. Isto tudo faz o desenlace muito mais doce. Para Fânia, este foi inicialmente um casamento de conveniência e de aparência. Mas não foi só a noiva humana que negou os seus favores ao marido; com a continuação da seca, não houve também fertilização da mãe-terra.

Na segunda parte da narrativa, o enredo de colonização retorna com uma vingança, apoiando-se fortemente no equilíbrio delicado da nova vinculação romântica. A Galileia, ou a mãe-terra (ou talvez a própria busca pioneira), exerce pressão sobre os sujeitos desta história, limitando a sua liberdade de escolha e forçando-os para dentro do seu molde. Lapid não parece muito 
desejosa de aceitar o veredicto do momento histórico, do "sonho (sionista) de redenção, ardendo como fogo nos ossos". Ela permitiu que Fânia desenvolvesse a sua subjetividade feminina apesar de e contra as pressões da visão coletiva, com todas as suas consequências trágicas. O mito da "grande mãe", o arquétipo da mãe-terra subjaz a esta obra. É este arquétipo que nutriu todos os mitos de um retorno à terra-mãe, inclusive o sionismo. E é esta conexão de imagens e metáforas que foi questionada nos últimos anos em Israel na tentativa de explicar o lugar problemático da mulher no etos sionista. A estrutura profunda do enredo de colonização é o de uma Mãe Terrível e de seu consorte condenado. No fracasso de Yehiel de conquistar a mãe-terra (ele morre de malária), os mitos primitivos de fertilidade exaurem-se mais uma vez. A essência do mito, somos lembrados, é uma repetição infindável. Permanecendo só, então, o script de colonização teria chegado a um impasse não fosse por sua intersecção dinâmica com o segundo enredo, o texto da heroína. O principal impulso psicológico do romance é a liberação da protagonista feminina do jugo das normas sociais impostas a ela pelas representantes da comunidade. Fânia, de uma adolescente ferida que atua sob coerção e foge ante a sua primeira experiência de dor e de frustração, transforma-se em uma mulher que persiste numa escolha consciente para concretizar o sonho pioneiro de seu falecido marido. Previsivelmente, Fânia adquire a independência por um processo de individuação em que ela transcende as normas ditadas a ela pelas figuras de mães que tentam lhe ensinar o "seu lugar natural". Ela atinge a maturidade após uma série de tarefas que assume a fim de salvar o marido e o lar da devastação causada pela mãe-natureza. Nós a encontramos irrompendo em um mundo antes dominado pelos homens. Ao mesmo tempo, ela não nega a sua feminilidade, sua distinção do mundo masculino que a rodeia. Seu código pessoal é definido, então, como a liberdade de escolher o melhor dos dois mundos, de mover-se livremente de um para o outro.

Romances como que ou quase históricos camuflam uma consciência feminista contemporânea e expressam, em diferentes graus de deslocamento, as lutas de suas autoras com questões de subjetividade feminina e limites de gênero. Em diversos romances recentes de autoras israelenses, preocupações contemporâneas foram projetadas em personagens "liberadas" de outro tempo e de outro lugar. 
Lapid, obviamente, sentiu que a sociedade israelense no início da década de 1980 aceitaria uma identidade "feminista" como uma projeção histórica.

Shifra Horn, por sua vez, em Arba Imahot (Quatro mães), de 1996, desenvolve uma versão feminina da história formadora da constituição da nação, no início do século XX, sobre o modelo dos patriarcas bíblicos.

A ficção hebraica moderna se sustenta em uma literatura em que abundam textos de autoria masculina, centrados em conflitos ideológicos, demandas por ação no domínio público e os dilemas de filhos em relação a legados paternos. Horn, assim como diversos outros escritores e escritoras, elaborou uma obra que convida o leitor a pensar e a repensar a carga da história judaica moderna à luz do relacionamento dentro da família, interrogando as narrativas históricas e buscando concepções alternativas de elaboração do texto.

Conhecemus o mito antigo pelo qual Deus prometeu a terra de Canaã à semente de Abraão. Como outras religiões e culturas, a judaica é baseada em mitos santificados e registrados nos relatos antigos, que contam sobre a origem dos hebreus e a revelação que Deus faz ao antigo patriarca, Abraão, do surgimento do povo de Israel e sua história. Deus escolheu Abraão para ser o pai deste povo, e seus descendentes, após uma seleção de três gerações, tornaram-se o povo escolhido, o povo de Israel.

O que Shifra Horn produziu é, na minha percepção, em uma das diversas leituras possíveis de Quatro mães, uma retomada da antiga temática patriarcal do surgimento do povo, excluindo dela, tanto quanto possível, os elementos masculinos, e uma releitura do texto bíblico, dando origem a uma leitura feminina.

Levando em consideração a celebração dos quinhentos anos de descobrimento do Brasil, refiz a leitura de Quatro mães de Shifra Horn. A releitura que se faz dos mitos fundadores da história do Brasil sugeriu um pensamento renovado sobre o que eu também denominaria de mito fundador de Israel ou, melhor dizendo, do judaísmo que desponta na velha nova pátria nos últimos cem anos.

Segundo o pensamento de Marilena Chaui, vive-se no Brasil a presença difusa de uma narrativa da origem. Esta narrativa, embora com uma antiguidade de alguns séculos, não cessa de se repetir porque opera como mito 
fundador. Mito no sentido antropológico: solução imaginária para tensões, conflitos e contradições que não encontram caminhos para serem resolvidos na realidade. Mito na acepção psicanalítica: impulso à repetição por impossibilidade de simbolização e, sobretudo, como bloqueio à passagem à realidade. Mito fundador porque impõe um vínculo interno com o passado como origem, isto é, com um passado que não cessa, que não permite o trabalho da diferença temporal e se conserva como perenemente presente. Um mito fundador é aquele que não cessa de encontrar novos meios para exprimir-se, novas linguagens, novos valores e ideias, de tal modo que, quanto mais parece ser outra coisa, tanto mais é a repetição de si mesmo.

Esta concepção de mito fundador pode ser percebida também na leitura do livro de Horn. Volto às origens do povo judeu: Abraão, Isaque, Jacó, as promessas de uma grande nação e de habitar a terra. As respectivas esposas, as matriarcas/mães, são tão conhecidas quanto os patriarcas/pais. Peguem-se estes elementos e refaça-se a leitura e interpretação dos atos. Quando as personagens foram os pais fundadores, os relatos referentes aos mesmos, registrados no livro de Gênese, não esconderam episódios menos louváveis, alguns menos humanos que outros, mas que, enfim, destinavam-se, segundo os intérpretes, a estruturar a história de um povo e, por isso, foram santificados. Abraão, temeroso diante de uma situação nova que talvez não pudesse controlar, apresenta a esposa como irmã no Egito e recebe benesses do faraó; seu relacionamento com a mulher foi então entendido como incestuoso; Isaque se deixa conduzir à Akedá, o sacrifício, e, mais tarde, ser enganado pela esposa e pelo filho; paralela à sua, paira a história de Ismael, o primogênito que não pôde ser herdeiro principal, e sua mãe, Hagar, banida. A história finda com a expulsão de ambos, a qual na prática, os faria morrer de sede. Jacó rouba a primogenitura de seu irmão. Pode-se ainda citar o relacionamento das filhas de Lot com seu pai, de que brotaram povos diversos, a beleza das matriarcas bíblicas e o seu penar por anos de esterilidade. Paralelamente ao texto bíblico, não faltam midrashim (relatos interpretativos de caráter muitas vezes folclórico) explanatórios para os diversos aspectos que a economia do texto original deixou de fora.

O que pretendo indicar é que o livro de Horn apresenta a sua posição de construção de pais fundadores ou, quem sabe, de mito fundador de uma 
parcela do judaísmo contemporâneo utilizando a linha feminina das matriarcas em contraste com a tradicional concepção bíblica patriarcal. As gerações femininas do romance iniciam-se com Mazal, uma órfã; seu nome significa destino. Então é a partir dela que se vê uma linha de destino diferente. A data talvez possa ser fixada em aproximadamente 1880, paralela ao desenvolvimento do sionismo moderno que culminaria com a criação do moderno Estado de Israel. A história de Sara, sua filha, sua beleza e longevidade, que fazem lembrar a matriarca bíblica, estarão presentes no decorrer de toda a obra. Ela somente morre quando o infortúnio da família se encerra com o nascimento de um menino, neto de sua neta, com o rompimento de uma dinastia de muitas distorções, e o estabelecimento de um descendente ao qual estará destinado um novo futuro. A mãe do menino nasce, sintomaticamente, em 1948, ano do surgimento do Estado. Os nomes da maior parte das personagens, femininas e masculinas, repetem os dos patriarcas e matriarcas bíblicos. O livro é recente e a autora não teve pejo em apresentar tantas aberrações quantas pudessem caber, ainda que, pela sutileza do trato, sejam apenas subentendidas: incesto, lesbianismo, filhos fora do casamento, adultério, idiotia, problemas sexuais.

Horn trabalha o seu enredo - a construção de sua versão do mito fundador, personagens e relacionamentos familiares - numa paródia ao texto bíblico. A paródia, no pós-modernismo, provoca, de forma paradoxal, uma confrontação direta com o político e o histórico. As referências paródicas à história restabelecem, em termos textuais, um diálogo com o passado e, talvez de forma inevitável, com o contexto social e ideológico no qual aquela é (e foi) produzida e vivida. A paródia é o análogo formal do diálogo entre passado e presente.

Pode-se verificar como isto funcionou em Arba imahot através de um sem- número de detalhes que se encerrarão quando a última figura feminina, Amal (nome que significa labuta), se casa com Yaakov (Jacó) e gera um filho. Amal, a última mulher da dinastia, inventa um pai inexistente: Moshê, Moisés - um policial; tendo ela nascido ou como resultado de um relacionamento de sua mãe com o árabe Muhamad ou quem sabe como resultado de um estupro coletivo, a escolha do nome Moshê equivaleria à posição do Muhamad muçulmano, o profeta. Além de um possível pai árabe, há também um pai inglês no enredo, o que indica as diversas contribuições à fundação ou à existência de 
Israel, através de laços não tão convencionais, remetendo ao abominado mandatário britânico como ao habitante árabe que, neste contexto, é um partícipe externo ao fazer do país. É óbvio que apenas utilizar estes nomes ainda não é suficiente para a concretização da paródia; a fragmentação e posterior seleção de um conjunto de atos e relacionamentos entre as personagens podem igualmente conduzir ao jogo com o texto histórico da criação do povo judeu.

A paródia pós-moderna caracteriza sua duplicidade paradoxal de continuidade e mudança, de autoridade e transgressão. A incorporação paradoxal do passado nas estruturas da paródia muitas vezes aponta para os contextos ideológicos de maneira um pouco mais óbvia, mais didática do que as outras formas. A paródia parece oferecer, em relação ao presente e ao passado, uma perspectiva que permite ao artista falar para um discurso a partir de dentro deste discurso, mas sem ser totalmente recuperado por ele. Por este motivo, a paródia parece ter se tornado a categoria denominada de "ex-cêntrico", daqueles que são marginalizados por uma ideologia dominante.

O centro aqui não é Abraão e sua genealogia, não é o Criador; a terra prometida já foi concedida; as guerras e as desgraças registradas na história são pano de fundo de tal promessa do início da formação do povo; o foco transposto para Sara e as demais mulheres - todas elas já fizeram parte da história em papéis mais ou menos secundários - propõe a releitura segundo a concepção das mulheres (personagens e autora) vivendo os tabus criados, estabelecidos e impostos pela sociedade dominada por um sistema patriarcal. Não mirar as promessas divinas de terra e povo, mas viver o dia a dia da terra onde casar, procriar, prover o alimento da família, amar e oferecer esperança é o essencial.

A Sara de Shifra Horn é a matriarca não só porque gerou uma descendência, mas porque a sua figura, que é também moldada segundo o modelo de alguma santa católica, com as rosas perfumadas e curativas, como a Virgem mexicana de Guadalupe, traz alento àqueles que a buscam. Após a sua morte é seu túmulo que se torna centro de peregrinação, não a Mearat hamachpelá, túmulo de matriarcas, localizado em Hebron. Na árvore vizinha ao local de sepultamento da benfeitora Sara pendem os braceletes hospitalares das mulheres que conseguiram ter filhos depois de visitar o túmulo. 
Horn parodiou melodramaticamente as histórias e as personagens femininas do mito fundador hebraico e, com isto, deu a sua contribuição ao desenvolvimento do imaginário do país. Imaginário que o povo imagina, que não vê todo dia na rua, mas gostaria de vivenciar; é a invenção de uma Sara reconstruída com alguns resquícios de uma Sara original, mas imaginada como alguém mais palpável, mais próxima, que pode ter ao mesmo tempo a imagem de uma estrela, como o mito da mulher mais bela com a sua cabeleira loira, desejada pelos homens, mas que também trabalha como lavadeira para alimentar a família; que é amaldiçoada e, ao mesmo tempo, ajuda os outros; cuja beleza, tão extraordinária que as palavras não são suficientes para descrevê-la, justifica o recurso da perpetuação pela descrição das fotos que a registraram em seu erotismo. A criação e o registro do imaginário nesta versão feminina fazem parte do mito criador do povo.

\section{Referências bibliográficas}

BERLOVITSH, Yafa. Haomnam feminizatsia shel hassifrut haisraelit? (Será mesmo uma feminização da literatura israelense?). Moznayim, vol. 66, n 9, agosto de 1992. CHAUI, Marilena. Brasil: mito fundador e sociedade autoritária. São Paulo: Editora Fundação Perseu Abramo, 2000.

ELBOIM-DROR, Rachel. Nashim bautopiot hatsioniot (Mulheres nas utopias sionistas). Katedra Letoldot Eretz Israel Veishuva, n 66, Yad Its'hak Ben Zvi, Jerusalém, dezembro de 1992.

FELDMAN, Yael S. Roman histori o "otobiografia bemassechá” (Romance histórico ou autobiografia mascarada). Siman kriá, nº 19, Tel Aviv, julho de 1985.

HORN, Shifra. Arba imahot. Or Yehuda: Maariv, 1996.

HUTCHEON, Linda. Poética do Pós-Modernismo. Rio de Janeiro: Imago, 1991. LAPID, Shulamit. Guei Oni. Jerusalém: Kéter, 1982. 